\title{
Tacrolimus Induced Early Graft Dysfunction Secondary to Acute Tubular Necrosis in Renal Transplant Recipient - A Case Report
}

\author{
HOQUE MT ${ }^{\mathrm{a}}$, MITRA ${ }^{\mathrm{b}}$, SAMDANI TS $^{\mathrm{c}}$, HOSSAIN $^{\mathrm{d}}$, ABEDIN Z $^{\mathrm{e}}$, MANSUR MA $^{\mathrm{f}}$
}

\begin{abstract}
Summary:
Acute tubular necrosis (ATN) is a medical condition involving damage of the tubular cells of the nephron following a toxic or ischaemic injury. If the cause of ATN is removed then recovery is likely. Calcineurin inhibitors (ciclosporin \& tacrolimus) are used as immunosuppressive agents in renal transplant recipient. But either of these two drugs can cause acute nephrotoxicity. A 62 years old known diabetic, hypertensive \& ESRD patient after undergoing living related donor renal transplantation started passing
\end{abstract}

\section{Introduction:}

The treatment options of End stage kidney disease (ESKD) is Renal replacement therapy (RRT) in the form of either dialysis (Haemodialysis or peritoneal dialysis) or renal transplantation. The central issue of renal transplant is suppression of allograft rejection. The conventional immunosuppressive drug protocol for renal transplantation is calcineurin inhibitor (CIN), mycophenolate mofetil (MMF) and Prednisolone ${ }^{1}$. The approval of clinical use of CIN in 1983 allowed significant expansion of kidney transplantation. But CINs can cause acute nephrotoxicity that may lead to acute allograft failure. The serum levels of these drugs do not correlate well with the extent of renal damage caused, and the clinical manifestation is nonspecific ${ }^{2,3,4}$.

a. Dr. Md. Tariful Hoque, Medical Officer, Medicine Unit, BIRDEM.

b. Dr. Palash Mitra, Assistant Registrar, Haemodialysis Unit, BIRDEM \& Transplant Unit, BADAS.

c. Dr. Tasrina Shamnaz Samdani, Medical Officer, CCU, BIRDEM.

d. Dr. Golzar Hossain, Senior Medical Officer, Haemodialysis unit, BIRDEM, Co-ordinator, Transplant unit, BADAS.

e. Dr. Zainal Abedin, Registrar, Haemodialysis unit, BIRDEM \& Transplant unit, BADAS.

f. Prof. Md. Abul Mansur, Professor \& Head, Haemodialysis unit, BIRDEM, Director, Transplant unit, BADAS.

Address of correspondence: Dr. Palash Mitra, Assistant Registrar, Haemodialysis unit, BIRDEM \& Transplant unit, BADAS, Dhaka, E.mail: palash_mtr@yahoo.com

Received: June 20, 2011

Accepted: December 22, 2011 significant amount of urine, but 12 hrs after transplantation the amount of urine output started to decrease and the patient became anuric after 17hrs of transplantation. Immediately the patient was evaluated thoroughly and calcineurin inhibitor (tacrolimus) was witheld. The patient again started passing urine from $4^{\text {th }} P O D$.

Key words: Tacrolimus, early graft dysfunction, acute tubular necrosis.

(Birdem Med J 2012; 2(1): 63-65)

This condition can be reversed if immediate measures are taken and thus the allograft function can be recovered. We are using the conventional immunosuppressive drug protocol in our centre. In this paper we report a case of acute tubular necrosis associated with tacrolimus in renal transplant recipient.

\section{Case report:}

A 62 years old male of known case of diabetes mellitus, hypertension, end stage kidney disease (due to diabetic nephropathy) on maintenance haemodialysis was admitted to BIRDEM hospital on $13^{\text {th }}$ January 2011 for renal transplantation. A successful well matched living related donor kidney transplantation was done on $18^{\text {th }}$ January 2011. According to immunosuppressive drug protocol the patient was given Inj. Basiliximab $20 \mathrm{mg}$ as induction and for maintenance he was given Cap. Tacrolimus, Tab. Mycophenolate mofetil and Tab. Prednisolone. The patient started passing urine on the OT table and passed about 6 liters of urine in first 12 hours. His urine output gradually decreased over the next few hours and he became anuric 17 hours after renal transplantation. Immediately the patient was thoroughly examined to find out any mechanical obstruction of the urine outflow tract or any other reversible cause that can explain the situation. The patient was asymptomatic, on clinical examination all his vitals were within normal limit, there was no anaemia, dehydration, oedema, respiratory distress, cough, chest pain, fever or any rash, his abdomen was 
soft with only mild tenderness around OT site. Urgent ultrasonogram of the transplanted kidney \& colour Doppler of renal artery showed normal size, shape \& echogenicity. But resistivity index (RI) of the renal artery was raised (0.87-0.91) and diastolic flow velocity was reduced in the renal artery and it's branches. His pre operative serum urea was $84 \mathrm{mg} / \mathrm{dl}$, s. creatinine was $6.2 \mathrm{mg} / \mathrm{dl}$ and during these incidence his s. urea was 90 $\mathrm{mg} / \mathrm{dl}$, s. creatinine was $4.6 \mathrm{mg} / \mathrm{dl}$, blood tacrplimus level was $7.44 \mathrm{ng} / \mathrm{ml}$, other bio-chemical parameters showed no significant abnormality and his Chest X-ray finding was also normal. So keeping in mind of two differential diagnosis of acute allograft rejection and Tacrolimus associated acute tubular necrosis, we started Methyl prednisolone pulse therapy and withhold the tacrolimus. A plan was made to undergo renal biopsy after 72 hours if the patient condition remain unchanged. Meanwhile over the next 48 hours his renal function deteriorated further to s.urea $186 \mathrm{mg} / \mathrm{dl} \& \mathrm{~s}$. creatinine $6.2 \mathrm{mg} / \mathrm{dl}$. The follow up ultrasonogram with colour Doppler of renal artery revealed narrowing in the proximal part of the renal artery beyond the anastomosis with reduced blood flow to the peripheral part and RI was 0.86 to 0.9 . Immediately renal angiogram was done but there was no obstruction to blood flow or any narrowing in anastomotic site. The patient was given a session of haemodialysis on $3^{\text {rd }}$ post operative day. On $4^{\text {th }}$ post operative day, the patient started to pass urine. Urinalysis showed pus cell: 3-5/ HPF, RBC: 20-30/HPF, Casts + , urine sodium was $88 \mathrm{mmol} / 1$ \& fractional excreation of sodium was calculated $4.59 \%$ which suggests sodium wasting due to ATN. His renal function started to improve steadily. USG of transplanted kidney with colour Doppler of renal artery showed normal size, shape \& echogenicity, A-V flow was seen upto peripheral part \& RI was $0.77-0.83$. On $5^{\text {th }}$ post operative day patient's s. urea \& creatinine level comes down to $74 \mathrm{mg} / \mathrm{dl} \& 2.3 \mathrm{mg} / \mathrm{dl}$ respectively. We started another calcineurin inhibitor, cyclosporine in low dose with an aim to gradually increase the dose. On $11^{\text {th }}$ post operative day the patient was discharged from hospital with a normal renal function of s.urea $36 \mathrm{mg} / \mathrm{dl} \& \mathrm{~s}$. creatinine $1.1 \mathrm{mg} / \mathrm{dl}$.

\section{Discussion:}

In the post transplant period, CINs may cause early graft dysfunction secondary to ATN due to CINs. Post transplant ATN is usually defined by the need for dialysis in the first week following transplantation or a failure to achieve a target decrease in creatinine level in the first days after transplantation ${ }^{5,6}$. ATN is caused by lack of oxygen to the kidney tissues ${ }^{7}$. The internal structures of the kidney particularly the tissues of the kidney tubules become damaged or destroyed. ATN affects 10$30 \%$ of renal transplants ${ }^{5,6}$. Studies have demonstrated that CINs causes vasoconstriction of the afferent and efferent glomerular arterioles ${ }^{8}$ and reductions in renal blood flow and glomerular filtration rate (GFR). The exact mechanism of vasoconstriction is unclear, but there appears to be substantial impairment of endothelial cell function, leading to reduced production of vasodilators (prostaglandins and nitric oxide) and enhanced release of vasoconstrictors (endothelin and thromboxane $)^{8,9,10}$. Increased sympathetic tone also may be present ${ }^{11}$, although renal vasoconstriction occurs even in denervated kidneys. The symptoms are usually non specific. Diagnostic clue includes oliguria to anuria, volume overload, deteriorating renal function as evidenced by rising blood urea, serum creatinine, fractional excretion of sodium may be high, urinalysis may show casts, kidney tubular cells \& RBC, urine sodium may be high, kidney biopsy may show acute tubular necrosis ${ }^{7}$. But the renal allograft biopsy carries the risk of hemorrhage, development of arteriovenous fistulae and possible graft loss. Some suggests that one should be conservative in performing invasive studies in such patients ${ }^{12,13}$, The allograft biopsy may be especially useful in poorly functioning kidneys, particularly after 14 days of established ATN, or in the presence of signs that suggest rejection ${ }^{13}$. As long as the kidney remains viable, no specific treatment is necessary other than administration of immunosuppressive medication curtailing the nephrotoxic CIN, haemodialysis and maintaining optimum hydration status. The nephrotoxic CIN can be replaced by the other drug of same group starting in low doses then gradually it can be increased to standard dose ${ }^{5,6}$. The duration of symptoms varies. The decreased urine output phase may last from a few days to 6 weeks or more. One or two days after urine output rises, symptoms reduce and laboratory values begin to return to normal ${ }^{7}$.

\section{Conclusion:}

In conclusion, we present a case of early graft dysfunction due to acute tubular necrosis induced by 
tacrolimus. Good recovery of graft function was achieved due to early detection \& withdrawl of offending drug. Early detection and management of the cause of ATN in early post transplant period is important not only for good recovery of the graft function but also delayed graft function on the basis of ATN, is an independent risk factor for acute rejection and suboptimal graft function at 1 year ${ }^{6}$.

\section{Conflict of interest:}

None

\section{Acknowledgement:}

Department of Radiology \& Imaging, Department of Internal Medicine \& Department of Nephrology of BIRDEM General Hospital.

\section{References:}

1. Philip F. Halloran, M.D., Ph.D. immunosuppressive drugs for kidney transplantation, N Engl J Med 2004;351:2715-29

2. Kahan BD. Drug therapy: Calcineurin inhibitors. N Engl J Med 1989; 321:1725.

3. Kopp JB, Klotman PE. Cellular and molecular mechanisms of calcineurin inhibitor nephrotoxicity. J Am Soc Nephrol 1990; 1:162-63.

4. de Mattos AM, Olyaei AJ, Bennett WM. Nephrotoxicity of immunosuppressive drugs: Long-term consequences and challenges for the future. Am J Kidney Dis 2000; 35:333.
5. Leichtman AB. Pathogenesis and pathology of early kidney allograft dysfunction. In: Norman DJ and Thorofare SW, editors. Primer on transplantation. The American Society of Transplant Physicians: 1998; 217-22

6. Boom H, Mallat MJ, De Fijter JW, Zwinderman AH, Paul LC. Delayed graft function influences renal function but not survival. Kidney Int 2000; 58:859-66

7. Molitoris B.A; Acute kidney injury; In: Goldman L, Ausiello D, editors Cecil Medicine. 23rd ed. Philadelphia, W.B. Saunders; 2007: 862-66.

8. Lanese DM, Conger JD. Effects of endothelin receptor antagonist on cyclosporine-induced vasoconstriction in isolated rat renal arterioles. J Clin Invest 1993; 91:2144.

9. De Nicola L, Thompson SC, Wead LM. Arginine feeding modifies cyclosporine nephrotoxicity in rats. J Clin Invest 1993; 92:1859-60.

10. Ruggenenti P, Perico N, Mosconi L. Calcium channel blockers protect transplant patients from cyclosporine-induced daily renal hypoperfusion. Kidney Int 1993; 43:706-08.

11. Scherrer U, Vissing SF, Morgan BJ. Cyclosporine-induced sympathetic activation and hypertension after heart transplantation. N Engl J Med 1990; 323:693.

12. Brophy D, Najarian JS, Kjellstrand CM. Acute tubular necrosis after renal trans-plantation.Transplantation 1980;29:245-48.

13. Flechner SM, Payne WD, van-Buren C, Kerman R, Kahan BD. The effect of cyclo-sporine on early graft function in human trans-plantation. Transplant 1983;36:268-72. 